\title{
Coordination Networks of Mercury(II) Halides and Polyether Ligand
}

\author{
Aurelien Crochet*[a] and Katharina M. Fromm*[a]
}

Keywords: Mercury; Halides; Coordination polymer; Crystal structure; Metal-organic frameworks

Abstract. New crystalline mercury halide adducts with polyether as ligands were isolated, characterized, and identified as trans$\left[\mathrm{Hg}^{\mathrm{II}} \mathrm{Cl}_{2}(\text { diox })_{2}\right]_{n}$ (1) and trans-[ $\left[\mathrm{Hg}^{\mathrm{II}} \mathrm{I}_{2}(\text { diox })\right]_{n}$ (2). The compounds were obtained from the metal halide salts in solution of 1,4-dioxane and can be considered as "cutting-out" products from the metal halide as they show similarity in the arrangement with starting compounds.

\section{Introduction}

We are interested in molecular compounds, especially oxygen donor adducts of metal halides, because they are useful as starting materials in the synthesis of low-dimensional polymeric compounds, i.e. clusters and coordination polymers or metal organic frameworks (MOFs). ${ }^{[1,2]}$ Indeed, since more than two decades, metal aggregates are used in the low-cost synthesis of superconductors and other oxide materials based on the sol-gel technique or as volatile precursors in the MOCVD (Metal Organic Chemical Vapor Deposition) process. One of the major problems of the synthesis of organo-metal(II) compounds, including the alkaline earth metal ions, is their possible tendency to form insoluble polymers. ${ }^{[3]}$ This is on one hand due to their low metal oxidation state II, which only allows two anionic ligands, and on the other hand, due to their ionic radii, which demand a high coordination number. A parry to prevent a high degree of oligomerization is the use of neutral Lewis-coordinating ligands such as monodentate THF or multidentate polyether ligands, which avoid any further metalmetal contacts by bridging ligands, saturating the metal cation. However, the chemistry of such metal halide or pseudo-halide adducts with neutral Lewis-coordinating ligands (usually nonpolar aprotic solvents) is still not systematically studied.

In this context, we have synthesized and characterized two new coordination polymers using a bidentate neutral Lewiscoordinating ligand 1,4-dioxane, in order to, in a fundamental way, know and understand better the chemistry of mercury halides in aprotic solvents. This ligand is commonly used in coordination chemistry to generate MOFs and supramolecular

\footnotetext{
* Dr. A. Crochet

E-Mail: aurecrochet@unifr.ch

* Prof. Dr. K. M. Fromm

Fax: +41-26-300-9738

E-Mail: katharina.fromm@unifr.ch

[a] Department of Chemistry

University of Fribourg

Chemin du musée, 9

1700 Fribourg, Switzerland

Supporting information for this article is available
}

structures. ${ }^{[4]}$ Secondly, we were interested to study the influence of the counterion on the coordination sphere of the metal cation using iodide and chloride salts, and compare it with the bromide salt derivative, which was published by Frey in 1971. [5]

\section{Results and Discussion}

The compound trans- $\left[\mathrm{Hg}^{\mathrm{II}} \mathrm{Cl}_{2}(\operatorname{diox})_{2}\right]_{n}(\mathbf{1})$ crystallizes in the tetragonal space group $14 / \mathrm{m}$, after being obtained by dissolution of $\mathrm{HgCl}_{2}$ in 1,4-dioxane (Figure 1). The core of the compound is based on one mercury(II) ion, connected in trans positions to two chloride atoms [2.313(5) $\AA$ ] and surrounded by four 1,4-dioxane molecules [2.760(9) $\AA$ ] in chair conformation $\left[+/-59(1)^{\circ}\right]$. Each dioxane molecule is connected to two mercury(II) atoms. With this connectivity system, we obtain a 2D coordination polymer. The distance between two $\mathrm{Hg}^{\mathrm{II}}$ atoms in the same plane is 7.2471(2) $\AA$ and the distance between two planes of $\mathrm{Hg}^{\mathrm{II}}$ is around $6 \AA$. In each plane of polymer, the macrocyclic succession of four $\mathrm{Hg}^{\mathrm{II}}$ and four 1,4-dioxane units leads to a cross-shaped cavity (Figure 2). The $\mathrm{HgCl}_{2}$ entities of the neighboring polymer planes above and below are offset to be centered on this cross-shaped cavity. The BVS method ${ }^{[6]}$ gives a value of 1.99 for the $\mathrm{Hg}^{\mathrm{II}}$.

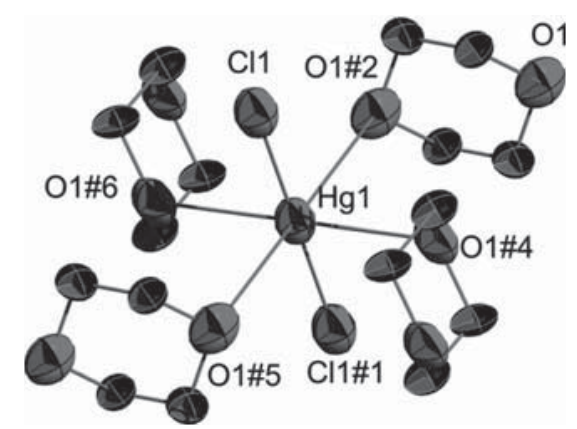

Figure 1. Molecular view of $\mathbf{1}$, hydrogen atoms are omitted for clarity, $\# 1=-x,-y,-z ; \# 2=1-x,-y, z ; \# 3=x, y,-z ; \# 4=y, 1-x, z ; \# 5=x-1$, $y, z ; 50 \%$ of probability. 

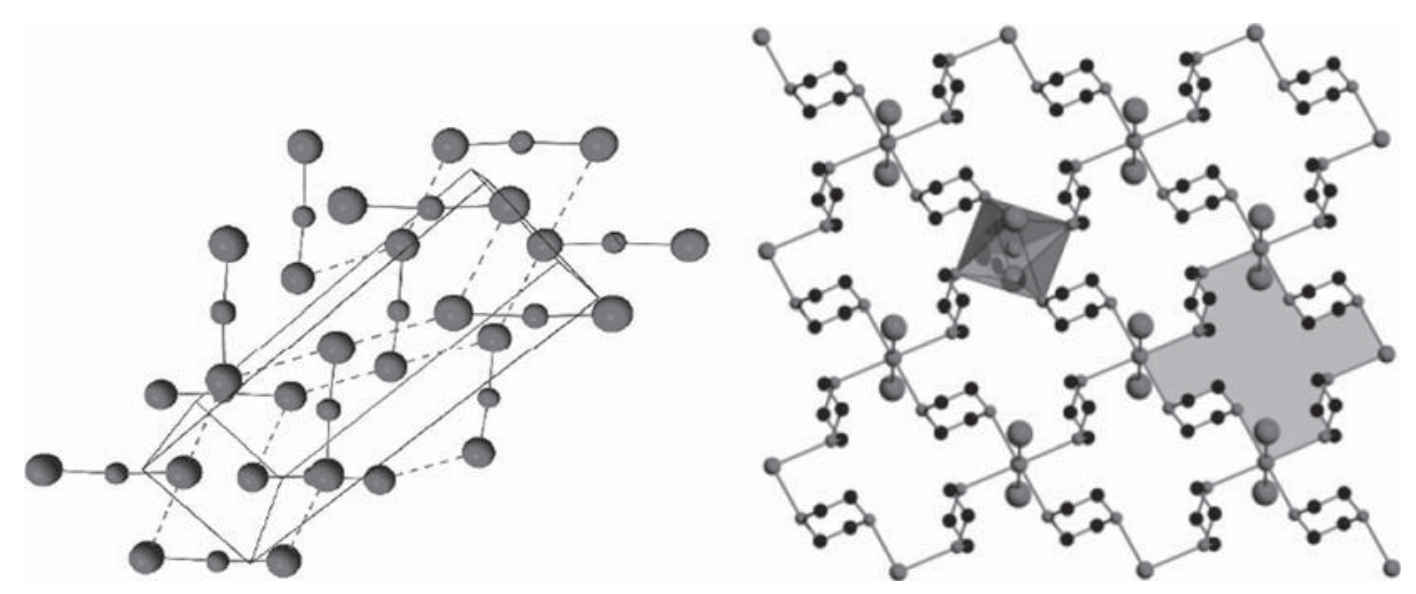

Figure 2. Packing of $\mathrm{HgCl}_{2}$ (left) with $\mathrm{Cl}-\mathrm{Cl}$ short contact in dash grey and molecular packing of $\mathbf{1}$ (right), mercury atoms of the next plane above and below are located offset over and under the shaded regions; hydrogen atoms are omitted for clarity; large spheres are chloride, small spheres are mercury ions.

In 1954, Hassel and Hvoslef published an article, in which a compound with different stoichiometry (1:1) crystallizes in space group $P \overline{1} .{ }^{[6]}$ In this compound, the distances $\mathrm{Hg}-\mathrm{O}$ and $\mathrm{Hg}-\mathrm{Cl}$ are $2.66 \AA$ (shorter than the distances in 1) and $2.34 \AA$, respectively (longer than in $\mathbf{1}$ ). Unfortunately, coordinates are not given and despite several trials we were not able to crystallize this compound.

Compound $\mathbf{1}$ is similar to $\left[\mathrm{HgBr}_{2}(\operatorname{diox})_{2}\right]_{n}$, as published by Frey in $1971,{ }^{[5]}$ with the same general arrangement of the building blocks. The two compounds have the same space group and the unit cells are similar, while variations are due to the size of the halide atoms. The BVS method gives a value of 1.84 for the $\mathrm{HgBr}_{2}$ complex presented by Frey. The two compounds follow the same crystallization procedure: filtration and crystallization of a saturated mercury halide solution in 1,4-dioxane. Comparing the crystal structure of the starting salts, e.g. $\mathrm{HgCl}_{2}$ with 1 (Figure 2), we can observe that the obtained structure of the 1,4-dioxane adduct corresponds to an intercalation of coordinated solvent into the salt. Thus, some short contacts within the salt were suppressed and replaced by coordination bonds, increasing the distance between the metal ions. Indeed we can notice that in $\mathrm{HgCl}_{2}$ like in $\mathbf{1}$, the two chlorides are collinear and strongly bound to mercury(II).

The second compound of $\mathrm{Hg}^{\mathrm{II}}$ halide with 1,4-dioxane is trans $-\left[\mathrm{Hg}^{\mathrm{II}} \mathrm{I}_{2}(\text { diox })\right]_{n}$ (2), which crystallizes in the triclinic space group $P \overline{1}$. In analogy to the previous compound, this compound is obtained by dissolution of $\mathrm{HgI}_{2}$ in 1,4-dioxane. The core of this compound is based on a mercury(II) ion connected in trans position to two 1,4-dioxane molecules $[2.76(2) \AA]$ in chair conformation $\left[+/-31(4)^{\circ}\right]$ and surrounded by four iodide atoms [2.610(2) and 3.444(2) $\AA$ ] (Figure 3). These four iodide and two oxygen atoms around the mercury ion afford a distorted square bipyramid. The angle of $\mathrm{I} 1-\mathrm{Hg} 1-$ I1\#1 is $89.40(4)^{\circ}$. This coordination of the mercury ions provides a succession of bipyramids connected by one edge of the base. The distance between two mercury ions is around $4.3 \AA$. Along the inorganic part of the compound, a chain of octahedra connected by a common edge is observed. Taking into account the 1,4-dioxane ligands, the $\mathrm{HgI}_{2}$-ladders are connected to- gether by 1,4-dioxane molecules (Figure S1, Supporting Information). The distance between two mercury atoms of two chains is around $8.2 \AA$. Thus, the combination of these two characteristics gives a $3 \mathrm{D}$ coordination polymer of $\mathrm{HgI}_{2}$. In this case the distance between two planes of $\mathrm{Hg}^{\mathrm{II}}$ atoms is around $8.2 \AA$. The BVS method gives a value of 1.83 for the $\mathrm{Hg}^{\mathrm{II}}$, which clearly indicates a weak coordination of the $1,4-$ dioxane.

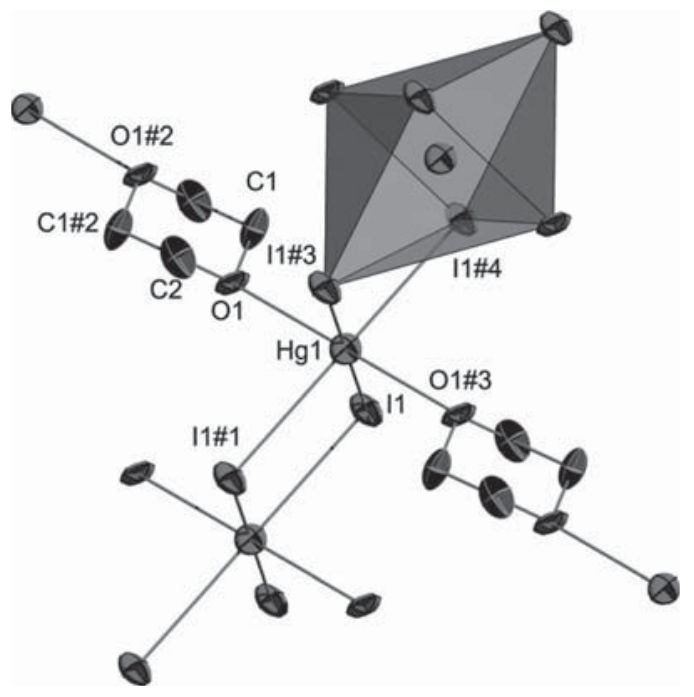

Figure 3. Molecular view of 2, hydrogen atoms are omitted for clarity, $\# 1=1-x, 1-y,-z ; \# 2=-x,-y, 1-z ; \# 3=-x, 1-y,-z ; \# 4=x-1, y$, $z ; 80 \%$ of probability, with polyhedron.

In the literature we can find two examples of $\mathrm{Hg}^{\mathrm{II}}$ dioxane complexes, with defined crystal structure. ${ }^{[5,7]}$ The first one is the $\mathrm{HgBr}_{2}$ complex, the second one is similar to 2 , with a chain of octahedra formed by coordination of trifluoroacetate $\left(\mathrm{AcF}_{3}\right)$ at two $\mathrm{Hg}^{\mathrm{II}}$ ions to form in total ladders of $\mathrm{Hg}\left(\mathrm{AcF}_{3}\right)_{2}$ connected in a second dimension by 1,4-dioxane (Table 1).

How does the compound $\mathbf{2}$ compare to the starting material $\mathrm{HgI}_{2}$ ? For the synthesis of $\mathbf{2}$, the starting product was the red $\mathrm{HgI}_{2},\left(\alpha-\mathrm{HgI}_{2}\right)$. Figure 4 shows the two polymorphs of mercury iodide. The salt was dried under vacuum by heating. Dur- 
Table 1. Comparison of $\mathbf{1}, \mathrm{HgBr}_{2}$ equivalent, 2 , and $\mathrm{Hg}\left(\mathrm{AcF}_{3}\right)_{2}$ complex and $\mathrm{Hg}^{\mathrm{II}}$ precursors.

\begin{tabular}{|c|c|c|c|c|c|c|}
\hline & 1 & {$\left[\mathrm{HgBr}_{2}(\operatorname{diox})_{2}\right]_{n}^{[9]}$} & 2 & $\mathrm{Hg}\left(\mathrm{AcF}_{3}\right)_{2}, \operatorname{diox}^{[7]}$ & $\mathrm{HgCl}_{2}$ & $\beta-\mathrm{HgI}_{2}$ \\
\hline $\begin{array}{l}\text { Formula } \\
\text { Lattice }\end{array}$ & $\begin{array}{l}\mathrm{C}_{8} \mathrm{H}_{16} \mathrm{Cl}_{2} \mathrm{HgO}_{4} \\
\text { tetragonal }\end{array}$ & $\begin{array}{l}\mathrm{C}_{8} \mathrm{H}_{16} \mathrm{Br}_{2} \mathrm{HgO}_{4} \\
\text { tetragonal }\end{array}$ & $\begin{array}{l}\mathrm{C}_{4} \mathrm{H}_{8} \mathrm{HgI}_{2} \mathrm{O}_{2} \\
\text { triclinic }\end{array}$ & $\begin{array}{l}\left(\mathrm{C}_{8} \mathrm{H}_{8} \mathrm{~F}_{6} \mathrm{HgO}_{6}\right)_{n} \\
\text { triclinic }\end{array}$ & $\begin{array}{l}\mathrm{Cl}_{2} \mathrm{Hg} \\
\text { orthorhombic }\end{array}$ & $\begin{array}{l}\mathrm{HgI}_{2} \\
\text { orthorhombic }\end{array}$ \\
\hline Space group & $I 4 / m$ & $I 4 / m$ & $P \overline{1}$ & $P \overline{1}$ & Pnma & $\mathrm{Cmc} 2_{1}$ \\
\hline$a / \AA ̊$ & $7.2471(2)$ & $7.454(3)$ & $4.3431(4)$ & $9.31(1)$ & 12.735 & 4.702 \\
\hline$b / \AA$ & $7.2471(2)$ & $7.454(3)$ & $7.6214(8)$ & $8.06(1)$ & 5.963 & 7.432 \\
\hline$c / \AA ̊$ & $12.0237(5)$ & $12.439(7)$ & $7.9252(8)$ & $4.783(5)$ & 4.324 & 13.872 \\
\hline$a /^{\circ}$ & 90 & 90 & $64.083(7)$ & $83.8(1)$ & 90 & 90 \\
\hline$\beta \mu^{\circ}$ & 90 & 90 & $84.466(8)$ & 100.1(1) & 90 & 90 \\
\hline$\gamma /{ }^{\circ}$ & 90 & 90 & $82.493(8)$ & 115.2(1) & 90 & 90 \\
\hline$V / \AA^{3}$ & $631.49(2)$ & $691.137(3)$ & $233.70(4)$ & $319.495(7)$ & 328.36 & 484.76 \\
\hline $\mathrm{Hg}-\mathrm{X} / \AA$ & $2.323(5)$ & $2.433(1)$ & $\begin{array}{l}2.610(2) \\
3.444(2)\end{array}$ & I & $\begin{array}{l}2.2449 \\
2.0880\end{array}$ & $\begin{array}{l}2.615 \\
2.620 \\
3.507 \\
3.510\end{array}$ \\
\hline $\mathrm{Hg}-\mathrm{O} / \AA ̊$ & $2.760(9)$ & $2.832(1)$ & $2.76(3)$ & $2.645(3)$ & l & I \\
\hline Diox torsion $/^{\circ}$ & $59(1)$ & $66(1)$ & $31(4)$ & $58(1)$ & l & I \\
\hline
\end{tabular}

ing the heating, a color change from red to yellow was observed (transition temperature of $\alpha-\mathrm{HgI}_{2}$ is $130{ }^{\circ} \mathrm{C}$ ). The return to room temperature is synonymous of a phase transition, the yellow $\mathrm{HgI}_{2}\left(\beta-\mathrm{HgI}_{2}\right)$ returns to red $\mathrm{HgI}_{2}$. Subsequently, 1,4dioxane is added to the compound. One could thus presume that the obtained structure of $\mathbf{2}$ is a derivative from the $\alpha$-phase but if we look carefully we can see that this structure is more a derivative from the $\beta$-phase than the $\alpha$-one. Indeed, like with $\mathrm{HgCl}_{2}$ and 1 compound $\mathbf{2}$ has collinear halogen ligands but in this case there are two different $\mathrm{HgI}$ sets, one with short bonds (Hg1-I1 and $\mathrm{Hg} 1-\mathrm{I \#} 3$ ) and one with long bonds (Hg1-I1\#1 and $\mathrm{Hg} 1-\mathrm{IH} 4)$. This binding motif comes directly from the $\beta-\mathrm{HgI}_{2}$, in which one also finds this binding motif but with three sets of collinear iodides (each with one short and two long).

We have shown earlier that the decomposition or evaporation of organic ligands may lead to high-temperature phases of e.g. oxide materials, ${ }^{[2]}$ which are otherwise only accessible by heating the compound. In a previous paper on barium iodide, we have determined that the longest bonds in the initial solidstate structure are cut stepwise, ${ }^{[8]}$ herein it seems that short bonds are cut first.

Comparison of the TGA of two mercury halide crystals of $\mathbf{1}$ and $\mathbf{2}$ shows two very different temperatures of evaporation for the 1,4-dioxane (Figure S2, Supporting Information). Indeed, in the case of complex $\mathbf{1}$, the evaporation temperature is around $180^{\circ} \mathrm{C}$, while for $\mathrm{HgI}_{2}$ complex the temperature is around $205^{\circ} \mathrm{C}$. If we look at the contribution of 1,4-dioxane to the bond valence, we can see that in the case of $\mathbf{1}$ the contribution $\mathrm{s}_{\mathrm{O} 1}$ is 0.1297 and 0.1425 in the case of 2 . The 1,4dioxane is more strongly coordinated to mercury in the case of the iodide complex. This can be explained by the fact that in the case of $\mathbf{2}$, we are further away from the initial crystal structure of one form of pure $\mathrm{HgI}_{2}$ than with $\mathbf{1}$, from $\mathrm{HgCl}_{2}$. We observed deformation in the 1,4-dioxane, especially in compound 2, with distances O1-C1 at 1.43(4) $\AA$ and O1-C2 at 1.26(4) $\AA$ and angle $\mathrm{C} 1-\mathrm{O} 1-\mathrm{C} 2$ at $119(3)^{\circ}$. This deformation is due to bonding of $\mathrm{O} 1$ to $\mathrm{Hg} 1$ and can be observed on IR spectra with a double band around $1040 \mathrm{~cm}^{-1}$. This band is a single band with compound $\mathbf{1}$ and pure 1,4-dioxane.

\section{Conclusions}

We have synthesized two new 1,4-dioxane adducts of mercury(II) halides and show the influence of the counterion on the crystal structure and on physical properties. Indeed, depending on the counterion and under the same conditions, we obtain two different crystal structures; the mercury chloride and the bromide give the same 2D coordination polymer type, but mercury iodide yields a 3D coordination polymer, derived from the high-temperature phase $\beta-\mathrm{HgI}_{2}$. With these two compounds and the addition of the $\mathrm{HgBr}_{2}$ and $\mathrm{Hg}\left(\mathrm{AcF}_{3}\right)_{2}$ analogs and by research of genesis of the crystal structures the driving force is saturation of the first coordination sphere of $\mathrm{Hg}^{\mathrm{II}}$, satu-

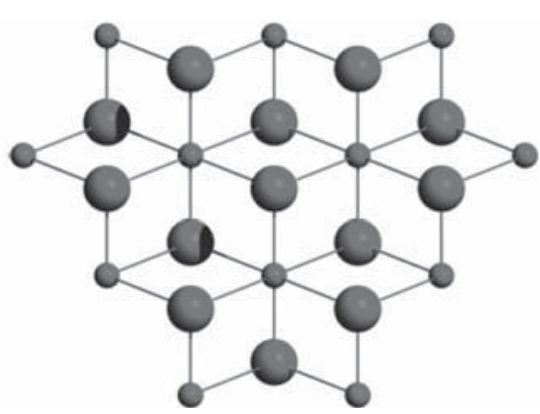

Figure 4. Molecular packing of (left) $\alpha-\mathrm{HgI}_{2}$, (right) $\beta-\mathrm{HgI}_{2}$. Large spheres are iodide, small spheres are mercury ions. 
ration done by the two bonding collinear halogen atoms (short $\mathrm{Hg}-\mathrm{X}$ bonds).

\section{Experimental Section}

General: All experiments were carried out in an inert argon atmosphere, using Schlenk techniques. ${ }^{[10]}$ THF was dried in a drying unit under argon and stored on molecular sieve; other solvents were bought dried and were stored on molecular sieve. The BVS calculations are performed with Valist. ${ }^{[11]}$ Single-crystal diffraction data were collected with a Stoe IPDS II theta, equipped with monochromated Mo- $K_{\alpha}$ radiation $(0.71073 \AA)$, IR and NMR spectra were recorded with a Bruker Tensor 27 and with a Bruker AM360, respectively. TGA were recorded with a Mettler Toledo TGA7SDTA851.

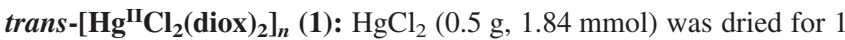
$\mathrm{h}$ under vacuum at $300{ }^{\circ} \mathrm{C}$ and afterwards dissolved in dried 1,4-dioxane $(30 \mathrm{~mL})$ and heated to reflux under magnetic stirring during $1 \mathrm{~h}$. Finally the solution was filtered under argon and the solution was slowly evaporated at $2 \times 10^{-2}$ mbar. Colorless single-crystals of $\mathbf{1}$ suitable for X-ray analysis grow in a yield of $80 \%$. IR: $\tilde{v}=2973$ (s), 2918 (m), 2901 (sh), 2857 (s), 2749 (sh), 2709 (sh), 1954 (w), 1443 (s), 1369 (sh), 1295 (sh), 1254 (s), 1113 (sh), 1091 (w), 1074 (w), 1041 (w), 858 (s), 674 (w), 639 (s) cm ${ }^{-1} .{ }^{1}$ H NMR ([D $]$ DMF, $\left.360 \mathrm{MHz}\right)$ : $\delta=3.48(\mathrm{~s}, 8 \mathrm{H}) \mathrm{ppm}$.

trans-[HgII $\mathbf{I}_{\mathbf{2}}$ (diox) $]_{\boldsymbol{n}}$ (2): $\mathrm{HgI}_{2}(0.5 \mathrm{~g}, 1.1 \mathrm{mmol})$ was dried for $1 \mathrm{~h}$ under vacuum at $300{ }^{\circ} \mathrm{C}$ and afterwards dissolved in dried 1,4-dioxane $(10 \mathrm{~mL})$ and heated to reflux under magnetic stirring during $1 \mathrm{~h}$. Finally the solution was filtered under argon and let at $4{ }^{\circ} \mathrm{C}$. Colorless single-crystals of $\mathbf{2}$ suitable for X-ray analysis grow in a yield of $70 \%$. IR: $\tilde{v}=2954$ (s), 2913 (m), 2886 (sh), 2854 (s), 2747 (sh), 2687 (sh), 1948 (w), 1443 (s), 1368 (sh), 1286 (sh), $1250(\mathrm{~s}), 1127$ (sh), 1110 (w), 1077 (w), 1043 (w), 1038 (w), 853 (s), 678 (w), 639 (s) cm ${ }^{-1} \cdot{ }^{1} \mathbf{H}$ NMR ([D $\left.\left.\mathrm{D}_{7}\right] \mathrm{DMF}, 360 \mathrm{MHz}\right): \delta=3.54(\mathrm{~s}, 8 \mathrm{H}) \mathrm{ppm}$.

X-ray Diffraction: All crystals were mounted on loops and all geometric and intensity data were taken from one single crystal. Data collection using Mo- $K_{\alpha}$ radiation $(0.71073 \AA$ ) was performed at $200 \mathrm{~K}$ with a STOE IPDS IIT diffractometer equipped with an Oxford Cryosystem open flow cryostat. ${ }^{[12]}$ The structures were solved and refined using full-matrix least-squares on $F^{2}$ with SHELX-97 package. ${ }^{[13]}$ All heavy atoms could be refined anisotropically. Hydrogen atoms were introduced as fixed contributors when a residual electronic density was observed near their expected positions.

Crystal Data for Compound 1: $\mathrm{C}_{8} \mathrm{H}_{16} \mathrm{Cl}_{2} \mathrm{HgO}_{4}, M=447.70 \mathrm{~g} \cdot \mathrm{mol}^{-1}$, tetragonal, $I 4 / \mathrm{m}$ (Nr. 87), $a=7.2471(2) ; c=12.0237(5) \AA ; \quad V=$ 631.49(4) $\AA^{3}, Z=2, \rho_{\text {calcd. }}=2.355 \mathrm{Mg} \cdot \mathrm{m}^{-3}, F(000)=420, T=200 \mathrm{~K}$, $\lambda=0.71073 \AA, \mu\left(\right.$ Mo- $\left.K_{\alpha}\right)=0.120 \mathrm{~mm}^{-1}, 5.2^{\circ}<\theta<25^{\circ}, 3357$ reflections of which 300 unique and 300 observed, 22 parameters refined, GOOF $\left(\right.$ on $\left.F^{2}\right)=0.95, R_{1}=\Sigma\left|F_{\mathrm{o}}-F_{\mathrm{c}}\right| / \Sigma F_{\mathrm{o}}=0.0336, w R_{2}=0.0987$ for $I>2 \sigma(I)$.

Crystal Data for Compound 2: $\mathrm{C}_{4} \mathrm{H}_{8} \mathrm{I}_{2} \mathrm{HgO}_{2}, M=542.49 \mathrm{~g} \cdot \mathrm{mol}^{-1}$, trigonal, $P \overline{1}(\mathrm{Nr} .2), a=4.3431(4) ; b=7.6214(8) ; c=7.9252(8) \AA ;$ $=64.083(7) ; \beta=84.466(8) ; \gamma=82.493(8)^{\circ} ; V=233.70(4) \AA^{3}, Z=1$, $\rho_{\text {calcd. }}=3.855 \mathrm{Mg} \cdot \mathrm{m}^{-3}, F(000)=234, T=200 \mathrm{~K}, \lambda=0.71073 \AA$, $\mu\left(\right.$ Mo- $\left.K_{\alpha}\right)=0.120 \mathrm{~mm}^{-1}, 4.7^{\circ}<\theta<25^{\circ}, 5459$ reflections of which 797 unique and 772 observed, 38 parameters refined, GOOF (on $F^{2}$ ) $=1.12, R_{1}=\Sigma\left|F_{\mathrm{o}}-F_{\mathrm{c}}\right| / \Sigma F_{\mathrm{o}}=0.0745, w R_{2}=0.1710$ for $I>2 \sigma(I)$.
Crystallographic data (excluding structure factors) for the structures in this paper have been deposited with the Cambridge Crystallographic Data Centre, CCDC, 12 Union Road, Cambridge CB21EZ, UK. Copies of the data can be obtained free of charge on quoting the depository numbers CCDC-812644 (1) and CCDC-812645(2) (Fax: +44-1223-336033; E-Mail: deposit@ccdc.cam.ac.uk, http://www.ccdc.cam.ac.uk).

Supporting Information (see footnote on the first page of this article): Color images are available in the supplementary materials as well additional figures and tables.

\section{Acknowledgement}

The authors thank the Swiss National Science Foundation as well as FriMat, and the University of Fribourg for most generous support.

\section{References}

[1] a) A. Crochet, K. M. Fromm, Z. Anorg. Allg. Chem. 2010, 636, 1484-1496; b) F. Gschwind, A. Crochet, W. Maudez, K. M. Fromm, Chimia 2010, 64, 299-302; c) J. Chen, A. Neels, K. M. Fromm, Chem. Commun. 2010, 46, 8282-8284; d) W. Maudez, K. M. Fromm, Helv. Chim. Acta 2009, 92, 2349-2356; e) T. V. Slenters, J. L. Sague, P. S. Brunetto, S. Zuber, A. Fleury, L. Mirolo, A. Y. Robin, M. Meuwly, O. Gordon, R. Landmann, K. M. Fromm, Materials 2010, 3, 3407-3429; f) K. M. Fromm, Coord. Chem. Rev. 2008, 252, 856-885.

[2] F. Gschwind, O. Sereda, K. M. Fromm, Inorg. Chem. 2009, 48, 10535-10547.

[3] a) D. C. Bradley, Adv. Inorg. Chem. Radiochem. 1972, 14, 259322; b) D. C. Bradley, Chem. Rev. 1989, 66, 1317-1322; c) D. C. Bradley, R. C. Mehrotra, D. P. Gaur, Metal Alkoxides, Academic Press, London, 1978; d) K. G. Caulton, L. G. Hubert-Pfalzgraf, Chem. Rev. 1990, 67, 969-995; e) K. M. Fromm, Chem. Commun. 1999, 1659-1660; f) K. M. Fromm, Chimia 2003, 57, 175-178; g) K. M. Fromm, E. D. Gueneau, G. Bernardinelli, H. Goesmann, J. Weber, M. J. Mayor-Lopez, P. Boulet, H. Chermette, J. Am. Chem. Soc. 2003, 125, 3593-3604.

[4] a) J. J. Morris, D. J. MacDougall, B. C. Noll, K. W. Henderson, Dalton Trans. 2008, 3429-3437; b) J. J. Morris, B. C. Noll, K. W. Henderson, Cryst. Growth Des. 2006, 6, 1071-1073; c) J. J. Morris, B. C. Noll, K. W. Henderson, Inorg. Chem. 2008, 47, $9583-$ 9591; d) Z. Zhang, S. Xiang, Q. Zheng, X. Rao, J. U. Mondal, H. D. Arman, G. Qian, B. Chen, Cryst. Growth Des. 2010, 10, 2372-2375.

[5] M. Frey, J. C. Monier, Acta Crystallogr., Sect. B 1971, 27, 24872490.

[6] O. Hassel, J. Hvoslef, G. Schultz, N. A. Sörensen, Acta Chem. Scand. 1954, 8, 1953.

[7] R. W. H. Small, Acta Crystallogr., Sect. B 1982, 38, 2886-2887.

[8] K. M. Fromm, Angew. Chem. Int. Ed. 1998, 37, 2799-2801.

[9] G. A. Jeffrey, V. M, Inorg. Chem. 1967, 6, 396.

[10] D. F. Shriver, The Manipulation of Air-Sensitive Compounds, McGraw-Hill Series in Advanced Chemistry, 1969.

[11] A. S. Wills, VaList, Programm available from www.ccp14.ac.uk.

[12] E. Blanc, D. Schwarzenbach, H. D. Flack, J. Appl. Crystallogr. 1991, 24, 1035-1041.

[13] a) M. C. Burla, R. Caliandro, M. Camalli, B. Carrozzini, G. L. Cascarano, L. de Caro, C. Giacovazzo, G. Polidori, R. Spagna, J. Appl. Crystallogr. 2005, 38, 381-388; b) G. Sheldrick, SHELX97, Program for Crystal Structure Refinement, University of Göttingen, Germany 1997. 